\title{
Effect of low-intensity therapeutic ultrasound on wound healing in rats subjected to third- degree burns ${ }^{1}$
}

\begin{abstract}
Rayanne Lisboa Mesquita', Pedro Iuri Castro da Silva ${ }^{\text {II }}$, Simone Haru Sawaki de Melo e Silva ${ }^{\text {III }}$, Kathlen Oliveira De Oliveira ${ }^{\text {IV }}$,

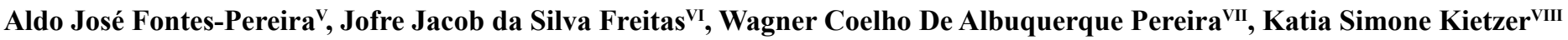

DOI: http://dx.doi.org/10.1590/S0102-865020160010000006

'Resident, Woman's Health Program, Universidade Federal de São Paulo (UNIFESP), Brazil. Conception and design of the study; acquisition, analysis and interpretation of data; manuscript writing.

IIFellow Master degree, Postgraduate Program in Surgery and Experimental Research, Laboratory of Morphophysiopathology Applied to Health/ CCBS, Universidade do Estado do Pará (UEPA), Brazil. Acquisition of data, manuscript preparation.

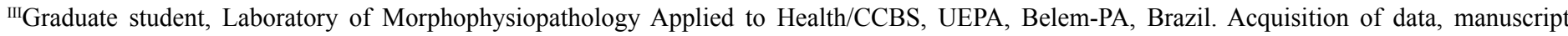
preparation.

${ }^{\mathrm{IV}}$ Resident, Elderly Residency Program, Hospital Universitário João de Barros Barreto, UEPA, Belem-PA, Brazil. Acquisition of data, manuscript preparation.

vFellow PhD degree, Biomedical Engineering Program, Laboratory of Ultrasound, Universidade Federal do Rio de Janeiro (UFRJ), Brazil. Scientific and intellectual content of the study, analysis and interpretation of data, statistical analysis, manuscript preparation.

${ }^{\mathrm{V}} \mathrm{PhD}$, Full Professor, Laboratory of Morphophysiology Applied to Health, Postgraduate Program in Surgery and Experimental Research, UEPA, Belem-PA, Brazil. Acquisition, analysis and interpretation of data.

VIIPhD, Associate Professor, Researcher 1B-CNPq, Laboratory of Ultrasound, Biomedical Engineering Program, UFRJ, Rio de Janeiro-RJ, Brazil. Scientific and intellectual content of the study, statistical analysis, critical revision.

VIIIPhD, Associate Professor, Laboratory of Morphophysiology Applied to Health, Postgraduate Program in Surgery and Experimental Research, UEPA, Belem-PA, Brazil. Scientific and intellectual content of the study, analysis and interpretation of data, statistical analysis, manuscript preparation.

\section{ABSTRACT}

PURPOSE: To determine the effectiveness of low-intensity therapeutic ultrasound (LITUS) on wound healing in rats with third-degree burns.

METHODS: Twenty rats were divided into the Control Group that comprised four rats without third-degree burns that did not undergo LITUS, the Burned Group (BG), comprising eight rats with third-degree burns that did not undergo LITUS, and the Burned with Treatment Group (BTG), comprising eight rats with third-degree burns that were administered LITUS. LITUS began $24 \mathrm{~h}$ after injury and involved daily applications for $8 \mathrm{~min}$ at $0.1 \mathrm{~W} / \mathrm{cm}^{2}$ for 14 days.

RESULTS: The BTG lost less weight than the BG $(\mathrm{Q}=2.75$; $\mathrm{p}<0.05)$. No visible differences were apparent among the groups' lesions on day 4. By the end of treatment, wound healing was more evident in the BTG. No statistically significant differences were found between the BG and the BTG in relation to the parameters measured using the histological changes in burn wound healing scoring system.

CONCLUSION: The LITUS protocol applied to the animals with third-degree burns accelerated the formation of fibrin-leukocyte crusts and significantly reduced weight loss. However, burn wound healing was not accelerated.

Key words: Physical therapy. Burn. Rats. Wound Healing. Ultrasonic Therapy. 


\section{Introduction}

Burns are a serious public health problem ${ }^{1,2}$. They represent one of the major causes of trauma in all age groups, and they lead to significant sequelae or even death. Indeed, 4.5 deaths/100.000 people per year occur in low and middle income countries as a consequence of burns ${ }^{2}$.

Large burns are one of the most aggressive causes of skin integrity losses. Burns are generally caused by flammable substances and overheated liquids ${ }^{2}$. Depending on the severity of the injury, epidermal necrosis can occur, which affects the dermis and the underlying tissues, and can lead to systemic changes that compromise other organs and tissues that are remote from the burnt area $^{3}$. In addition, hypovolemic shock and infectious or inflammatory diseases can occur, which are among the most challenging situations that patients with burns and their care teams have to confront.

The skin's recovery process is long, and it causes permanent changes that compromise the esthetic appearances of patients who have been burnt ${ }^{2,4}$. These changes cause contractures ${ }^{5}$ and limit motion, which, in addition to the esthetic issues, can affect individuals socially, economically, and emotionally ${ }^{2,6}$.

The treatment of burns is challenging. Several clinical and surgical approaches are being developed to reduce wound healing times and minimize the sequelae ${ }^{2,7}$. Physical therapy offers resources, including low-intensity therapeutic ultrasound (LITUS), which can help to accelerate the burn wound-healing process $^{8}$ and can prevent or reduce adhesions. LITUS is a commonly used therapeutic tool that enhances healing processes in a range of injuries ${ }^{9}$ by accelerating the inflammatory phase and stimulating neovascularization ${ }^{10}$, collagen synthesis, and fibroblast proliferation ${ }^{9,11}$. Accordingly, LITUS can hasten healing by encouraging the formation of a functional and esthetically satisfactory scar, and, as such, it provides non-invasive ${ }^{9}$ and lowcost therapy.

Research into large burns has gained greater attention from researchers because of the importance of the skin's physiological function. However, few studies have been published that have investigated the effect of conventional LITUS on the healing of third-degree burns. However, treatment with LITUS can have negative effects, because the equipment's parameters are not standardized, and the treatment itself might be inadequate ${ }^{9,12}$. Accordingly, new studies investigating the use of LITUS in the treatment of burns are required. Therefore, this study determined the effectiveness of LITUS that is commonly utilized in physical therapy clinics on the wound healing and tissue repair processes of third-degree scalding burns in rats.

\section{Methods}

This prospective, longitudinal, and descriptive study analyzed the application of LITUS to rats that had been subjected to third-degree burns.

Twenty male adult Wistar rats (Rattus norvegicus), aged between 90 days and 120 days and weighing 230-300g, were used for the experiment. During the experiment, the rats were kept in a room in which the humidity, noise, and temperature $\left(22^{\circ} \mathrm{C}\right)$ levels were controlled, and in a cycle comprising $12 \mathrm{~h}$ dark and $12 \mathrm{~h}$ light. The rats were randomly assigned to six cages, with each cage containing between two and four animals. The cages were covered with clean straw, and the animals had access to filtered water and food ad libitum.

All of the experimental procedures were performed at the Laboratory of Morphophysiopathology Applied to Health/CCBS of Pará State University (UEPA). The study was conducted after receiving approval from the Ethics Committee on Animal Use (Comitê de Ética em Uso de Animais) at UEPA (protocol number 09/2012), and it complied with the Guide for the Care and Use of Laboratory Animals ${ }^{13}$.

\section{Experimental groups}

The animals were divided into three groups, namely, the Control Group (CG) that did not receive third-degree burns or LITUS ( $n=4)$, the Burned Group (BG) that received third-degree burns and was not administered LITUS $(\mathrm{n}=8)$, and the Burned with Treatment Group (BTG) that received third-degree burns and was treated with LITUS $(\mathrm{n}=8)$, which was applied $24 \mathrm{~h}$ after the injuries and daily for $8 \mathrm{~min}$ for 14 days.

\section{Burn protocol}

Scalding water at $100^{\circ} \mathrm{C}$ was used to burn $30 \%$ of the animals' body surfaces. To ensure that the burnt area characterized a large burn, a template was made (Figures 1A and 1B) that was based on that developed by Walker and Mason ${ }^{14}$, and it incorporated modifications that were created by the Assistive Technology Laboratory at UEPA. A galvanic sheet was used for the burn template that was $7 \mathrm{~cm}$ wide and $28 \mathrm{~cm}$ long. Its interior was coated with insulating rubber and ethylene-vinyl acetate; hence, the template thermally insulated the parts of the body that 
were not to be exposed to scalding. The central region of the burn template was open and corresponded to the location and area of the thermal injury.

The total body surface area A (Figure 1C) relative to the animal's body mass was calculated using the following Equation $1^{14}$ :

$$
A=K \cdot W^{2 / 3} \text { Equation } 1
$$

where,

$A=$ total body surface area in $\mathrm{mm}^{2}$;

$K=10$ (constant ratio); and

$W=$ weight in grams.

The thermal injury corresponded to $30 \%$ of the rat's body surface area A.

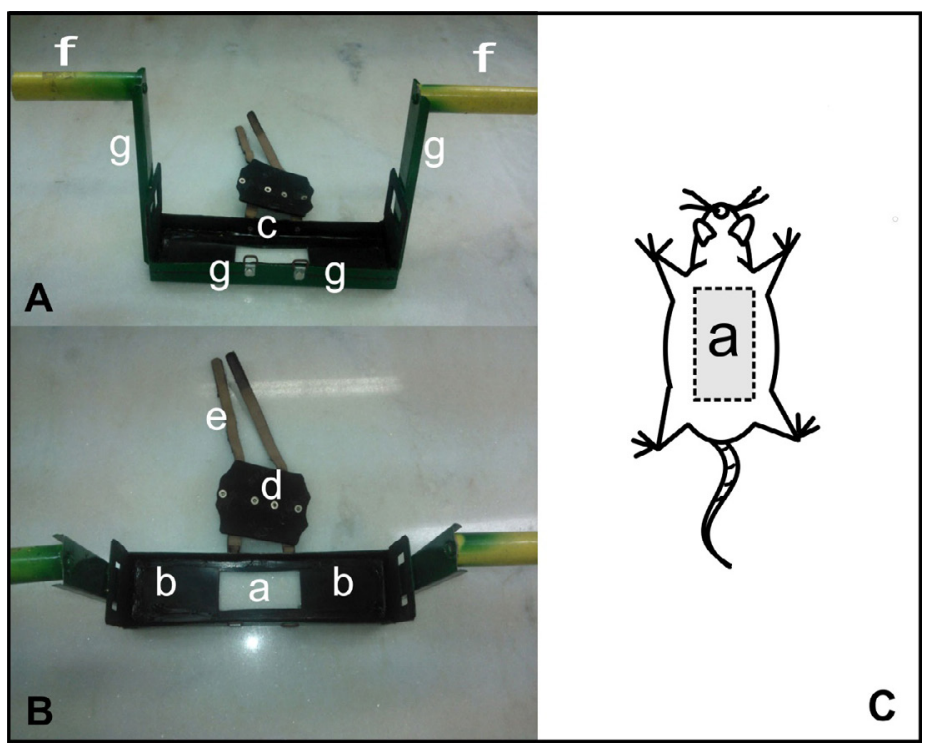

FIGURE 1 - A. The burn template. c: ethylene-vinyl acetate, f: wood support, g: galvanized sheet. B. The burn template. a: surface area $(30 \%$ of the rat's surface area), b: insulating rubber, d: insulating vest. C. The area of the burn on the animal's back.

Before being burnt, the animals were given analgesia in the form of manipulated Tramadol ${ }^{\circledR}(5 \mathrm{mg} / \mathrm{kg})$ that was administered orally via a gavage tube. Then, the animals were anesthetized using intraperitoneally injected Ketamina ${ }^{\circledR}(50-70 \mathrm{mg} / \mathrm{kg})$ and Xilazina $^{\circledR}(5-10 \mathrm{mg} / \mathrm{kg})$. After being anesthetized, the animals' backs were shaved, and they were immobilized and placed on the template in the supine position. Then, the template containing the animal was immersed for $10 \mathrm{~s}$ into water at $100^{\circ} \mathrm{C}$. This procedure resulted in non-lethal third-degree burns ${ }^{15}$. After being burnt, the animals, including those in the CG, were given analgesia orally using Tramadol ${ }^{\circledR}(5 \mathrm{mg} / \mathrm{kg})$, which was administered via a gavage tube every $12 \mathrm{~h}$ for 5 consecutive days.

\section{Animal preparation for LITUS treatment}

After being burnt, the animals were kept at room temperature until the anesthesia wore off to avoid hypothermia and death. Subsequently, the animals were placed individually in acrylic rat cages where they had access to filtered water and food ad libitum. To prevent the contamination of the injuries, the cages were covered with clean straw. The animals' weights were measured on the day of the injury, then on days $4,7,10,13$, and 15 when they were euthanized.

\section{Treatment protocol}

LITUS began $24 \mathrm{~h}$ after the burn injuries, and comprised daily applications of LITUS for 14 consecutive days using an Avatar III TUS0203 (KLD Biosistemas Equipamentos Eletrônicos Ltda., Amparo, SP, Brazil). To resemble clinical practice, pulsed LITUS at $3 \mathrm{MHz}$ was applied to the contours of the wounds using a spatial average temporal average (SATA) intensity of $0.1 \mathrm{~W} / \mathrm{cm}^{2}$, a $20 \%$ loading cycle, $32 \mathrm{~Hz}$ modulation, and a $2.5 \mathrm{~cm}^{2}$ effective radiating area, and LITUS was applied for $8 \mathrm{~min}$ in a circular motion.

To apply the LITUS, the animals were manually restrained with the burnt back region accessible to the treatment. The lesion was cleaned with saline and covered with a polyvinyl chloride (PVC) film that was $10.5 \mathrm{~mm}$ thick. Hydrogel was subsequently placed on the PVC film to couple the ultrasound transducer.

\section{Histological analysis}

The animals were euthanized by decapitation on day 15. The injured and surrounding areas of skin were removed with a scalpel. The skin removed comprised three zones, namely, the wound area (burnt skin), the area surrounding the wound, representing the transition from the burnt skin to the adjacent skin, and the adjacent skin. The excised skin was fixed in $10 \%$ buffered formalin for $48 \mathrm{~h}$ in preparation for histological processing. The tissue sections were stained using hematoxylin and $\operatorname{eosin}^{16}$. The histological analyses were performed using a trinocular microscope equipped with an Axio Scope A1 image-capturing system (Carl Zeiss Microscopy LLC, Thornwood, NY, USA) that consisted of an HRC AxioCam camera and AxioVision Release 4.7.2 software. Two evaluators, comprising a dermatologist and a pathologist, used the histological changes in burn wound healing scoring system ${ }^{16}$ to perform blind histological evaluations of the reepithelization, granulation, inflammation, and angiogenesis. 


\section{Statistical analyses}

The sample size was determined based on a value of $\alpha=0.05$, three groups, including one control group, and a test power of $80 \%$. To examine differences in the animals' weights and histological scores, the Kolmogorov-Smirnov normality test and the analysis of variance (ANOVA) were used [F(model degrees of freedom, residual degrees of freedom)]. The Kruskal-Wallis one-way ANOVA by ranks [H(degrees of freedom)] was used for weight-loss and quantitative histological analysis, then Dunn's post hoc test [Q] was applied, as appropriate. A significance level of $\alpha=0.05$ was used. SigmaStat software, version 3.5 (Systat Software Inc., San Jose, CA, USA) was used for the statistical analyses.

\section{Results}

A weight-loss analysis along the 15 days for each group was performed. The weight-loss variations in $\mathrm{CG}[\mathrm{F}(5,18)=1.74 ; \mathrm{p}$ $=0.177]$ and BTG $[\mathrm{H}(5)=8.42 ; \mathrm{p}=0.135]$ showed no statistically significant difference. On the other side, the weight-loss variation for the BG group was statistically significant $[F(5,40)=3.20 ; p=$ $0.016]$.

When comparing the groups together, there was a statistically significant difference among them in relation to weight loss $[\mathrm{H}(2)=7.98 ; \mathrm{p}=0.018]$ (Figure2) and the post-test findings revealed that this difference was only between the BG and BTG $[\mathrm{Q}=2.75 ; \mathrm{p}<0.05]$. The analysis of the coefficients of variation $(\mathrm{CV})$ demonstrated that the BTG $(\mathrm{CV}=0.06)$ had sustained less weight variation during the study compared with the $\mathrm{BG}(\mathrm{CV}=$ $0.11)$ and the $\mathrm{CG}(\mathrm{CV}=0.07)$.

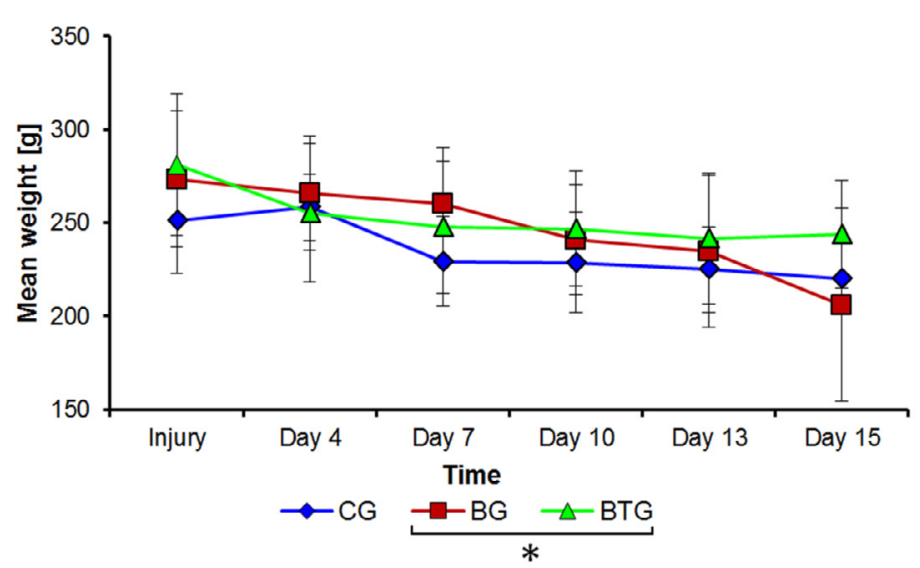

FIGURE 2 - Weight variations within the Control Group (CG), Burned Group (BG), and the Burned with Treatment Group (BTG) during the experimental period. Data presented are the means \pm standard deviations. *: post-test revealed difference only between groups BG and BTG $[\mathrm{Q}=$ $2.75 ; \mathrm{p}<0.05]$.
Regarding the macroscopic appearances of the burns, there were no differences between the groups from day 2 to day 4 following the injuries. On day 5, the animals in the BG had large unhealed wounds and the animals in the BTG were at a more advanced stage of healing, because the wounds were covered with fibrin-leukocyte crusts. On day 14 , healing was more evident in the BTG compared with the BG, which was inferred from the presence of darker and visibly larger crusts (Figure 3).

BG
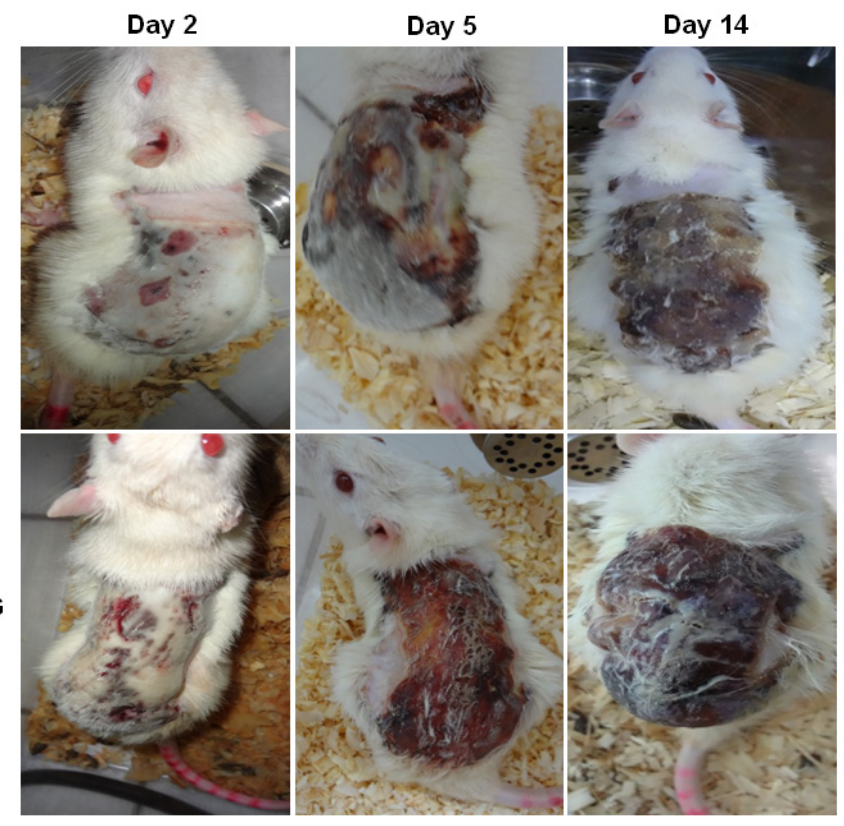

FIGURE 3 - Macroscopic appearance of the burns on the animals from the burned group (BG) and the burned with treatment group (BTG) on days 2,5 , and 14 after the scalding injury.

The qualitative histological analysis showed the presence of typically irregular and dense arrangements of collagen fibers (Figures 4A and 4B) within the reticular dermis of the skin from the animals in the CG. The skin from the animals in the BG showed that the superficial layers, namely, the epidermis and a major part of the dermis, had been destroyed, and that eschar and a dense inflammatory infiltrate were present between the remaining collagen fibers. The arrangement of the collagen fibers had changed compared with the CG (Figures 4C and 4D). In the BTG, the inflammatory cell infiltrate was not as dispersed among the collagen fibers, but, instead, the cells were clustered. The appearance of the collagen fibers in the skin from the BTG was similar to that in the skin from the $\mathrm{CG}$, because they comprised thick fibers that were arranged in different directions and they had an undulating appearance with many eosinophilic fibers, which is 
the typical appearance of normal dense connective tissue (Figures $4 \mathrm{E}$ and $4 \mathrm{~F})$.

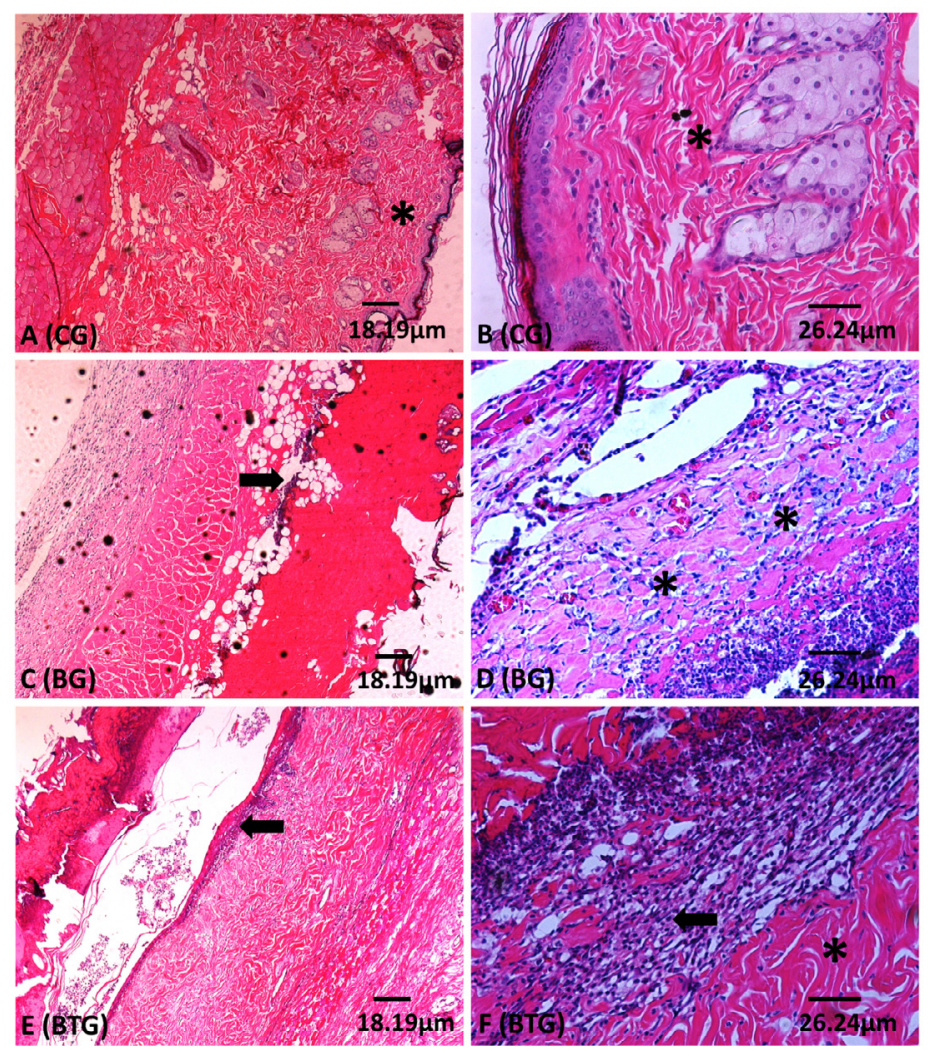

FIGURE 4 - The collagen fibers (asterisk) within the skin from the study animals. A. Control Group (CG) (hematoxylin and eosin [H\&E], $\times 5$ ). B. $\mathrm{CG}(\mathrm{H} \& \mathrm{E}, \times 10)$. C. An inflammatory cell infiltrate (arrow) is evident among the remaining collagen fibers in the Burned Group (BG) (H\&E, $\times 5)$. D. The arrangement of the collagen fibers in the BG $(H \& E, \times 10)$. E. Inflammatory cells (arrow) within the Burned with Treatment Group $(\mathrm{BTG})(\mathrm{H} \& \mathrm{E}, \times 5)$. F. The collagen fibers in the skin from the BTG have a thicker appearance (asterisk) and the inflammatory cells (arrow) appear to be in streaks $(\mathrm{H} \& \mathrm{E}, \times 10)$.

The coagulation areas that included the presence of eschar and inflammatory cell infiltrates, were similar in the skin from the animals in the BG and BTG (Figures 5A and 5B, respectively). However, in the areas of hyperemia, the thickness of the epidermis differed between the BG (Figure 5C) and BTG (Figure 5D). The epithelial tissue within the skin of the animals from the BTG was thicker, particularly within the basal layer region. In the areas of stasis, the skin from the animals in the BG had thinner epidermal layers (Figure 5E) compared with the skin from the animals in the BTG (Figure 5F). The epidermis of the skin from the BTG animals showed intense proliferative activity within the basal layer, which is characteristic of reepithelization (Figures 5D and 5F).
The muscle fibers within the skin from the CG animals were well circumscribed with narrow spaces between them (Figure $5 \mathrm{G})$. The muscle fibers within the skin from the BG animals had irregular outlines and there was more space between the fibers, with loosely arranged muscle fascicles, thick endomysia, and many fibroblasts present (Figure 5H). Compared with the BG, the skin from the BTG had loosely arranged muscle fascicles and the arrangement of the muscle fibers was more orderly (Figure 5I). The hypodermis was disorganized in the skin from the animals in the BG (Figure 5H) and the BTG (Figure 5I) compared with the skin from the animals in the $\mathrm{CG}$ (Figure $5 \mathrm{G}$ ).
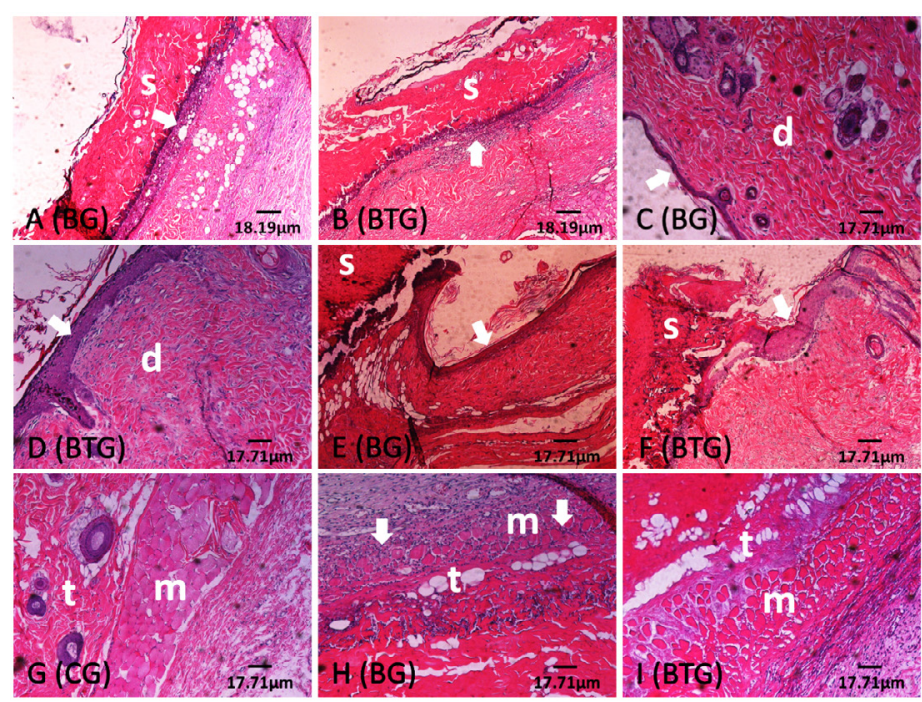

FIGURE 5 - Coagulation areas in the skin from the A. Burned Group (BG) (hematoxylin and eosin $[\mathrm{H \& E}], \times 5)$ and the B. Burned with Treatment Group (BTG) $(\mathrm{H} \& \mathrm{E}, \times 5)$ showing crusts (s) and inflammatory cell infiltrates (arrows). The hyperemia area in the $\mathbf{C}$. skin from the BG has a thinner epidermis (arrow) and dermis (d) (H\&E, $\times 10)$, and the hyperemia area in the D. skin from the BTG has a thicker epidermis (arrow), especially on the basal layer, and dermis (d) (H\&E, $\times 10)$. The stasis area in the $\mathbf{E}$. skin from the BG shows the presence of a crust (s) and a thinner epidermis (arrow) $(\mathrm{H} \& \mathrm{E}, \times 10)$, and the stasis area in the F. skin from the BTG shows the presence of a crust (s) and a thicker epidermis (arrow) (H\&E, $\times 10)$. Muscle tissue (m), fibroblasts (arrow), and the hypodermis $(\mathrm{t})$ in skin from the G. Control Group $(\mathrm{CG})(\mathrm{H} \& \mathrm{E}$, $\times 10)$, H. BG $(\mathrm{H} \& \mathrm{E}, \times 10)$, and I. BTG $(\mathrm{H} \& \mathrm{E}, \times 10)$.

The quantitative histological analysis conducted using the histological changes in burn wound healing scoring system determined statistically significant differences among the groups with respect to reepithelization $[\mathrm{H}(2)=17.00 ; \mathrm{p} \leq 0.001]$, granulation tissue $[\mathrm{H}(2)=9.48 ; \mathrm{p}=0.009]$, inflammation $[\mathrm{H}(2)=$ $8.62 ; \mathrm{p}=0.013]$, angiogenesis $[\mathrm{H}(2)=7.71 ; \mathrm{p}=0.021]$. To discover which groups are responsible for such differences, the post-test was applied. It was found that the groups BG and BTG present 
statistical differences when compared to the CG, nevertheless, they presented no statistical differences between each other (Figure 6).

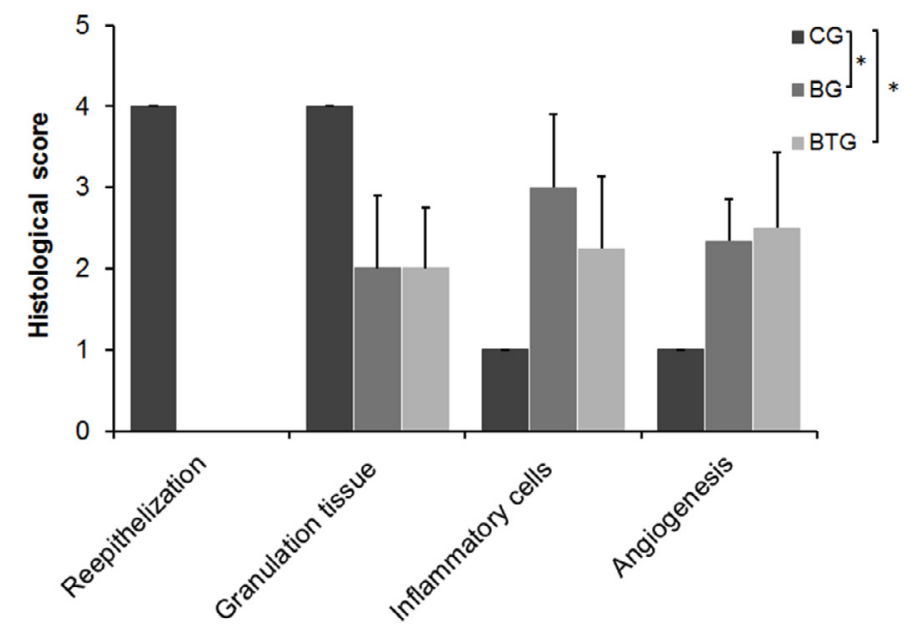

FIGURE 6 - Quantitative histological analysis of the control group (CG), Burned Group (BG), and the Burned with Treatment Group (BTG), based on the reepithelialization, granulation, inflammation, and angiogenesis criteria of the histological changes in burn wound healing scoring system. *post-test revealed differences between CG and BTG and between CG and BG.

\section{Discussion}

A severely burnt individual's weight declines as a consequence of the high level of energy consumption, which subsequently leads to muscle tissue loss and malnutrition ${ }^{17}$. Hence, it is necessary to accelerate the healing process to minimize tissue loss and malnutrition. In this study, the burns covered $30 \%$ of the body surface and can be considered as extensive and with systemic commitment ${ }^{15,18}$. The BG group was the only one to significantly lost weight along the 15 days. Additionally, this weight loss was also significant when compared to the BTG group, for the same period. In the BG, two animals died, which may have been related to complications associated with the burns and the animals' generally inferior physical condition compared with the BTG animals, and this concurs with previously published reports ${ }^{17}$.

The BG animals showed higher amounts of weight loss after day 7. This finding is consistent with research previously conducted by Wu et al. ${ }^{17}$ who evaluated severely burnt rats, and found that they continuously lost weight, that the weight loss intensified between days 7 and 14 after the injuries, and that it was accompanied by decreases in muscle mass.

After 14 days, the BTG animals had developed larger fibrin-leukocyte crusts than the BG animals. This is the most characteristic part of the healing process, because it is indicative of the new tissue that is growing to fill in the defect. The crust originates from the fibrin coagulum and inflammatory exudate that serves as a provisional matrix for the next stage of healing ${ }^{19}$. Ferreira et al. ${ }^{7}$ found similar outcomes after 14 days in Wistar rats that had sustained cutaneous injuries and were treated with conventional LITUS at $1.5 \mathrm{MHz}$ and administered at a SATA intensity of $30 \mathrm{~mW} / \mathrm{cm}^{2}$. Emesen ${ }^{20}$ applied pulsed ultrasound at $0.75 \mathrm{MHz}$ and $3 \mathrm{MHz}$ at intensities of $0.1 \mathrm{~W} / \mathrm{cm}^{2}$ and $0.18 \mathrm{~W} / \mathrm{cm}^{2}$. They suggest that ultrasound therapy is useful in accelerating the inflammatory and early proliferative stages of repair.

In the current study, LITUS administered at a SATA intensity of $0.1 \mathrm{~W} / \mathrm{cm}^{2}$ was applied for $8 \mathrm{~min}$ each day for 14 days. A SATA intensity of $0.1 \mathrm{~W} / \mathrm{cm}^{2}$ was used because this reflects the SATA intensity that is available within physical therapists' ultrasound equipment, which differs from the more expensive equipment used in research into healing. Hence, we ensured that any potential use of such a therapeutic modality would be less costly and more accessible. In addition, a SATA intensity of 0.1 $\mathrm{W} / \mathrm{cm}^{2}$ appeared to accelerate the inflammatory processes and cellular proliferation ${ }^{21}$. Lower LITUS intensities, like those used in this study, reduce cellular damage by using pulsed acoustic energy, which induces fibroblast proliferation and promotes tissue repair in other types of injuries ${ }^{9,22}$. The duration of the treatment was chosen to enable us to determine the effects of LITUS within a short timeframe.

The similarities between the BTG and BG with regard to the levels of inflammatory cell infiltration when the tissues were analyzed qualitatively and quantitatively using the histological changes in burn wound healing scoring system, concurs with the findings from the study by Piedade et al. ${ }^{23}$. These investigators analyzed the effects of LITUS (1 MHz pulsed ultrasound (50\%) at $0.57 \mathrm{~W} / \mathrm{cm}^{2}$ for $5 \mathrm{~min}$ ) on lacerated muscle healing in rats, and they observed a reduction in the inflammatory infiltrate in the group that was treated immediately; however, 24 days later, both the BTG and the BG had developed similar inflammatory infiltrates. Freitas et al. ${ }^{11}$ asserted that the purpose of using pulsed LITUS $\left(0.4,0.6\right.$, and $\left.0.8 \mathrm{~W} / \mathrm{cm}^{2}\right)$ in wound healing is to accelerate the inflammatory phase, that is, the migration and proliferation of the fibroblasts that are fundamental to the healing process. The inflammatory response plays a fundamental role in the supply of growth factors and in the cytokine signaling that are responsible for cell and tissue movements and are important for the subsequent stages of wound repair and contraction ${ }^{24,25}$.

The histological analysis of the skin's structure in the areas of hyperemia and injury stasis revealed the changes 
in the epidermis, and it had increased in thickness in the BTG compared with the BG. These observations are similar to those made by Bem et al. ${ }^{26}$ who suggested that epidermal thickening had occurred because the cells within the basal layer of the epidermis had been stimulated to undergo mitosis. The basal layer contains keratinocytes that are essential to reepithelization, and distinct stem cells are present in the basal layer that migrate throughout the contour of the wound to fill in the injured area ${ }^{27}$.

Ferreira et $\mathrm{al}^{7}{ }^{7}$ applied LITUS for $10 \mathrm{~min}$ on alternate days, and treatment began immediately after the injuries during the acute inflammatory phase. Planimetric measurements enabled these investigators to verify that the animals treated with LITUS had smaller injuries compared with the group that did not receive treatment, and they concluded that LITUS stimulated healing after 14 days of treatment.

In contrast to this study, Cambier and Vanderstraeten ${ }^{8}$ evaluated the effect of pulsed LITUS at $3 \mathrm{MHz}$ that was administered at a SATA intensity of $0.25 \mathrm{~W} / \mathrm{cm}^{2}$, a loading cycle of $20 \%$, and a frequency of $100 \mathrm{~Hz}$. They applied LITUS to 20 female Fisher rats with third-degree burns in 5-min treatment sessions over the course of 6 weeks, but the histological data failed to reach statistical significance. The investigators concluded that LITUS had no effect on healing burns.

In the BTG animals, the centripetal proliferation of the basal layer was suggestive of an attempt at reepithelization. Reepithelization plays a major role in reorganizing the function of the epidermis, which is responsible for providing mechanical protection, local temperature regulation, and protection against external agents.

The collagen fibers in the skin from the BTG animals had an appearance that was comparable with that of the collagen fibers in the skin from the CG animals, and their collagen fibers were better organized than those of the BG animals. When skin sustains an injury, it requires collagen to repair and restore its anatomical structure and function. However, when there are considerable levels of disorganized collagen deposits within the injured area, the skin loses its normal morphological structure and its function is compromised, which leads to fibrosis ${ }^{27}$. There were no substantial differences between the BTG and BG with regard to vascularization, thereby indicating that angiogenesis, which is associated with an organism's response to the presence of ischemic tissues, that is, tissues that are growing rapidly and have increased rates of metabolic activity, was not accelerated by the LITUS protocol, which suggests that LITUS had no effect on the injuries.
Further studies are needed to broaden our knowledge about the effects of LITUS on people who have sustained burn injuries. Accordingly, we propose that other LITUS treatment protocols should be tested, including different treatment times and doses. Adopting non-invasive methods to monitor the entire healing process, including magnetic resonance imaging and quantitative ultrasound ${ }^{28}$, would enable in vivo observations of the effects of LITUS to be undertaken. It would also be interesting to determine and analyze the levels of oxidative stress, since it is present during the healing of large burn injuries ${ }^{29}$. We suspect that LITUS accelerates the regeneration process mainly by enhancing the cellular permeability which allows the arriving of macrophages to the damaged area. Those macrophages will boost the inflammatory process, releasing the growth factors and starting the regenerative process as well as diminishing the oxidative stress. So this cascade of events reduces the systemic inflammation and nutritional deficit, thus controlling the treated rats' weight loss and the death risk $^{11}$.

\section{Conclusions}

The low-intensity therapeutic ultrasound protocol applied to the animals with third-degree burns in this study accelerated the formation of fibrin-leukocyte crusts and it reduced weight loss. After 14 days of treatment, there were no statistically significant differences between the $\mathrm{BG}$ and BTG animals with respect to the reepithelization, granulation, inflammation, and angiogenesis criteria. Thus, the findings from this study suggest that within the parameters used in this research, the effects of LITUS are more closely associated with reducing weight loss than accelerating wound healing, and that it is potentially useful as an additional low-cost tool for the treatment of burn injuries.

\section{References}

1. Popescu FC, Busuioc CJ, Mogoşanu GD, Pop OT, Pârvănescu H, Lascăr I, Nicolae CI, Mogoantă L. Pericytes and myofibroblasts reaction in experimental thermal third degree skin burns. Rom J Morphol Embryol. 2011;52(3 Suppl):1011-7. PMID: 22119818.

2. Mock C. WHO joins forces with International Society for Burn Injuries to confront global burden of burns. Inj Prev. 2007 Oct;13(5):303.

3. Oliveira Fd, Bevilacqua LR, Anaruma CA, Boldrini Sde C, Liberti EA. Morphological changes in distant muscle fibers following thermal injury in Wistar rats. Acta Cir Bras. 2010 Nov/ Dec;25(6):525-8. PMID: 21120285.

4. Grishkevich VM. Ankle dorsiflexion postburn scar contractures: anatomy and reconstructive techniques. Burns. 2012 Sep;38(6):8828. PMID: 22325850. 
5. Dematte MF, Gemperli R, Salles AG, Dolhnikoff M, Lanças T, Saldiva PH, Ferreira MC. Mechanical evaluation of the resistance and elastance of post-burn scars after topical treatment with tretinoin. Clinics (Sao Paulo). 2011;66(11):1949-54. PMID: 22086527.

6. Medeiros ADC, Ramos AMDO, Dantas Filho AM, Azevedo RDCFD, Araújo FLFB. Tratamento tópico de queimaduras do dorso de ratos com ácido hialurônico. Acta Cir Bras. 1999 Oct/ Dec;14(4):203-7. doi: 10.1590/S0102-86501999000400010.

7. Ferreira AS, Barbieri CH, Mazzer N, Campos AD, Mendonça AC. Measurement of healing area using planimetry after applying low intensity ultrasound to the skin of rats. Rev Bras Fisioter. $2008 \mathrm{Sept} /$ Oct;12(5):351-8. doi: 10.1590/S1413-35552008000500003.

8. Cambier DC, Vanderstraeten GG. Failure of therapeutic ultrasound in healing burn injuries. Burns. 1997 May;23(3):248-9. PMID: 9232286.

9. Dalecki D. Mechanical bioeffects of ultrasound. Annu Rev Biomed Eng. 2004;6:229-48. PMID: 15255769.

10. Hogan RD, Burke KM, Franklin TD. The effect of ultrasound on microvascular hemodynamics in skeletal muscle: effects during ischemia. Microvasc Res. 1982 May;23(3):370-9. PMID: 7099026.

11. Freitas TP, Gomes M, Fraga DB, Freitas LS, Rezin GT, Santos PM, Silveira PC, Paula MM, Pinho RA, Streck EL. Effect of therapeutic pulsed ultrasound on lipoperoxidation and fibrogenesis in an animal model of wound healing. J Surg Res. 2010 Jun;161(1):168-71. PMID: 19577772.

12. Steiss JE, Adams CC. Effect of coat on rate of temperature increase in muscle during ultrasound treatment of dogs. Am J Vet Res. 1999 Jan;60(1):76-80. PMID: 19577772.

13. National Research Council (US) Committee for the Update of the Guide for the Care and Use of Laboratory Animals. Guide for the care and use of laboratory animals. Washington (DC): The National Academies Press; 2011.

14. Walker HL, Mason AD Jr. A standard animal burn. J Trauma. 1968 Nov;8(6):1049-51. PMID: 5722120.

15. Barbosa RCC, Guimarães SB, Vasconcelos PRCD, Chaves CR, Vasconcelos PRLD. Metabolic effects of glutamine in rats subjected to scald burn. Acta Cir Bras. 2003 Nov/Dec;18(6): 537-41. doi: 10.1590/S0102-86502003000600008.

16. Galeano M, Altavilla D, Bitto A, Minutoli L, Calò M, Lo Cascio PL, Polito F, Giugliano G, Squadrito G, Mioni C, Giuliani D, Venuti FS, Squadrito F. Recombinant human erythropoietin improves angiogenesis and wound healing in experimental burn wounds. Crit Care Med. 2006 Apr;34(4):1139-46. PMID: 16484928.

17. Wu X, Wolf SE, Walters TJ. Muscle contractile properties in severely burned rats. Burns. 2010 Sep;36(6):905-11. PMID: 20381255.

18. de Oliveira BCC, de Oliveira F, Martini DT, Prisco CRD, da Silva Riguetti MM, Liberti EA, de Campos Boldrini S. The relative effects of severe burn injury and pre-and post-natal protein deprivation on mandibular condyle morphology. Histol Histopathol. 2010; 25(1): 45-54. PMID:19924640.

19. Diegelmann RF, Evans MC. Wound healing: an overview of acute, fibrotic and delayed healing. Front Biosci. 2004 Jan;9:283-9. PMID: 14766366.

20. Emsen IM. The effect of ultrasound on flap survival: An experimental study in rats. Burns. 2007 May;33(3):369-71. doi: 10.1016/j. burns.2006.08.007

21. Young SR, Dyson M. Effect of therapeutic ultrasound on the healing of full-thickness excised skin lesions. Ultrasonics. 1990 May;28(3):175-80. PMID: 2339476.

22. Fontes-Pereira AJ, Teixeira RDC, Oliveira AJBD, Pontes RWF, Barros RSMD, Negrão JNC. The effect of low-intensity therapeutic ultrasound in induced fracture of rat tibiae. Acta Ortop Bras. 2013 Jan/Feb;21(1):18-22. doi: 10.1590/S1413-78522013000100003.
23. Piedade MC, Galhardo MS, Battlehner CN, Ferreira MA, Caldini EG, de Toledo OM. Effect of ultrasound therapy on the repair of gastrocnemius muscle injury in rats. Ultrasonics. 2008 Sep;48(5):403-11. PMID: 18384832.

24. Huet E, Vallée B, Szul D, Verrecchia F, Mourah S, Jester JV, Hoang-Xuan T, Menashi S, Gabison EE. Extracellular matrix metalloproteinase inducer/CD147 promotes myofibroblast differentiation by inducing alpha-smooth muscle actin expression and collagen gel contraction: implications in tissue remodeling. FASEB J. 2008 Apr;22(4):1144-54. PMID: 17965264.

25. Eming SA, Krieg T, Davidson JM. Inflammation in wound repair: molecular and cellular mechanisms. J Invest Dermatol. 2007 Mar;127(3):514-25. PMID: 17299434.

26. Bem DMD, Maciel CD, Zuanon JA, Neto CB, Parizotto NA. Análise histológica em tecido epitelial sadio de ratos Wistar (in vivo) irradiados com diferentes intensidades do ultrassom. Rev Bras Fisioter. 2010 Mar/Apr;14(2):114-20. doi: 10.1590/S141335552010005000010 .

27. Gantwerker EA, Hom DB. Skin: histology and physiology of wound healing. Clin Plast Surg. 2012 Jan;39(1):85-97. PMID: 22099852.

28. Fontes-Pereira A, Matusin DP, Rosa P, Schanaider A, von Krüger MA, Pereira WCA. Ultrasound method applied to characterize healthy femoral diaphysis of Wistar rats in vivo. Braz J Med Biol Res. 2014 May;47(5):403-10. doi: 10.1590/1414-431X20143443.

29. Parihar A, Parihar MS, Milner S, Bhat S. Oxidative stress and antioxidative mobilization in burn injury. Burns. 2008 Feb;34(1):6-17.

PMID: 17905515

\section{Acknowledgements}

To Dr Sérgio H. Hirata and Dr Nilceo S. Michalany for applying the scoring system of the histological changes in burn wound healing to this work, and Prof. Jorge Lopes Rodrigues Júnior for constructing the burn template.

\section{Correspondence:}

Katia Simone Kietzer

Universidade do Estado do Pará, Centro de Ciências Biológicas e da Saúde

Travessa Perebebuí, Marco

66087670 Belém - PA Brasil

Tel.: (55 91)3087-0301

kkietzer@yahoo.com

Received: Sept 20, 2015

Review: Nov 15, 2015

Accepted: Dec 17, 2015

Conflict of interest: none

Financial sources: CNPq, CAPES and FAPERJ

${ }^{1}$ Research performed at Laboratory of Morphophysiopathology Applied to Health/CCBS, Universidade do Estado do Pará (UEPA), Brazil. 